\title{
Caregiver burden among family caregivers of incurable cancer patients in two eastern Mediterranean countries
}

\author{
Samy A. Alsirafy ${ }^{1,2}$, Radfan Nagy ${ }^{3}$, Amneh D. Hassan', Radwa Fawzy 3,4 , Ahmad A. M. Abdelhafeez ${ }^{3}$, \\ Marahim O. Husein ${ }^{5}$, Mohammed A. Almashiakhi ${ }^{5}$, Saad H. Alabdullateef ${ }^{1}$, Saeed A. Alghamdi ${ }^{5}$ and \\ Ashraf M. Elyamany $y^{5,6}$
}

\begin{abstract}
Background: Although family caregivers (FCs) play an important role in the care provided to incurable cancer patients in our region, little is known about the burden they experience.

This study was conducted to determine the prevalence of caregiver burden (CB) among FCs of incurable cancer patients in two Eastern Mediterranean countries and to identify factors that may be associated with significant CB.

Methods: The study included 218 FCs, 165 from Egypt and 53 from Saudi Arabia. The 22-item Zarit Burden Interview (ZBI-22) was used to assess caregiver burden CB. Significant CB was defined as a ZBI-22 score $\geq 21$. The assistance with basic ADLs was classified into 3 levels according to FCs'assistance with early/middle/late-loss basic ADLs. The relationship between $C B$ and the assistance with ADLs and other factors was studied.

Results: The mean (SD) ZBI-22 score among FCs was 23.4 (9.3) and the majority (128/218, 59\%) had significant CB. Eighty-nine percent of FCs assisted with at least one basic ADL. Assistance with late-loss basic ADLs, best supportive care treatment plan and poorer performance status were associated with higher $\mathrm{CB}(p<0.0001,=0.018$ and $=0.005)$. However, in logistic regression analysis, only assistance with late-loss ADLs was independently associated with significant CB (OR=3.4 [95\%Cl:1.2-9.7], $p=0.024)$.

Conclusion: A substantial proportion of $F C$ s of incurable cancer patients in our region experience significant $C B$. Family caregivers assisting with late-loss basic $A D L s$ are at risk of significant $C B$ and should be routinely screened for CB.

Keywords: Family caregivers, Palliative care, Incurable cancer, Caregiver burden, Activities of daily living, Egypt, Saudi Arabia, Eastern Mediterranean
\end{abstract}

\section{Background}

In 2020, the estimated number of cancer deaths in the WHO Eastern Mediterranean region (EMRO) exceeded 450,000 deaths [1]. The only realistic treatment for these

*Correspondence: s.alsirafy@ksmc.med.sa; alsirafy@kasralainy.edu.eg

1 Palliative Care Unit, Hemato-Oncology Department, King Saud Medical

City, Riyadh, Saudi Arabia

Full list of author information is available at the end of the article hundreds of thousands of dying cancer patients is palliative care which is ideally initiated from the date of diagnosis of incurable cancer aiming at improving their quality of life as well as that of their families [2]. In addition to being recipients of palliative care; family caregivers (FCs) of incurable cancer patients play important roles in the care of their related patients. They usually provide a lot of important tasks: assistance with activities of daily living (ADLs), administrative tasks (e.g., case management), 
instrumental tasks (e.g., accompanying the cancer patient to medical appointments and housekeeping tasks), navigation tasks (e.g., finding a doctor) and social support activities (e.g., providing companionship) [3-5].

Informal caregivers of cancer survivors have many unmet needs related to comprehensive cancer care, emotional and psychological wellbeing, daily activities, relationships, information and spirituality [6-8]. The important roles performed by informal caregivers and their unmet needs are associated with significant caregiver burden (CB) [9-12]. The CB experienced by caregivers of cancer patients is associated with poorer quality of life among them [13]. This in turn is expected to have a negative impact on the care they provide to cancer patients. Therefore, it is essential to identify FCs with $\mathrm{CB}$ and intervene to relieve their burden.

The burden of caregiving among FCs of cancer patients is generally under-researched in the Eastern Mediterranean region. A number of studies from Iran showed that FCs of patients with different stages of cancer experience significant $\mathrm{CB}$ which was associated with poorer quality of life and identified some factors predicting higher burden like shorter time since cancer diagnosis and higher family distress $[10,13,14]$. One study from the southern region of Saudi Arabia reported a moderate/severe CB among $50 \%$ of caregivers of hospitalized terminally ill cancer patients [15].

The aim of this study was to determine the prevalence of CB among FCs of incurable cancer patients in two Eastern Mediterranean countries (Egypt and Saudi Arabia) and to study factors that may be associated with significant $\mathrm{CB}$, including $\mathrm{FCs}$ ' assistance with ADLs of patients.

\section{Methods}

This observational cross-sectional study was conducted in the period from November 2019 to January 2021 and included 244 FCs of patients with incurable cancer at Kasr Al-Ainy Center of Clinical Oncology and Nuclear Medicine, Kasr Al-Ainy School of Medicine, Cairo University, Cairo, Egypt and the Hemato-Oncology Department, King Saud Medical City, Riyadh, Saudi Arabia.

\section{Participants}

Participants were Arabic-speaking adult (>18years) informal FCs of adult patients with incurable cancer. Incurable cancer patients were defined as patients with advanced cancer for which no further anti-cancer treatment is possible (best supportive care plan) / anti-cancer treatment is given with palliative intent (palliative anticancer treatment plan). Palliative care is ideally initiated for these patients from the date of diagnosis of incurable cancer and sometimes it is the only possible management plan. Only one FC per patient was included and nonfamily informal caregivers were excluded.

Purposive-convenience sampling method was used to recruit FCs accompanying their related patients attending the oncology outpatient clinic or those admitted to the oncology inpatient ward. Family caregivers were approached to participate in the study and interviewed by authors RN, RF and AA in Egypt and by $\mathrm{AH}$ and $\mathrm{MOH}$ in Saudi Arabia.

\section{Measurement tools and data collection}

Caregiving burden among FCs was assessed using the 22-item Zarit Burden Interview (ZBI-22). We used the Arabic for Saudi Arabia version of the ZBI-22 [16] which was obtained from Mapi Research Trust, Lyon, France (https://eprovide.mapi-trust.org/). Each of the ZBI-22 items is scored on a 5-point scale ranging from 0 to 4 . The total score is the sum of the 22 items score and ranges from 0 to 88 with higher scores indicating higher burden. Missing interview items were replaced by the mean score of answered items. The sum of interviews with replaced missing values was rounded to the nearest integer. Interviews with $>6$ missing items were excluded from analysis [17]. Participants with a ZBI score $\geq 21$ were considered to have significant burden [18].

The assistance provided by FCs with the following basic ADLs was assessed: dressing, combing hair, brushing teeth, bathing, toilet use, cleansing, moving between locations, transfer to/from chair, bed mobility and eating. The level of ADLs loss was graded according to Morris et al. [19] into early loss (dressing and personal hygiene), middle loss (toilet use, transfer and locomotion) and late loss (bed mobility and eating). Bathing was considered middle loss ADLs. The level of assistance provided by FCs with ADLs was graded as level 1 (no assistance / assistance with any early loss ADL), level 2 (assistance with any middle loss ADL \pm assistance with any early loss ADL) and level 3 (assistance with any late loss $\mathrm{ADL} \pm$ assistance with any early/middle loss ADL).

In addition to caregiver's burden and assistance with ADLs; information about characteristics of FCs, patients and cancer was collected (Table 1).

\section{Sample size}

Using the 10 outcome events per predictor variable (EPV) rule and considering a $70 \%$ prevalence of $\mathrm{CB}$ using the ZBI-22 cutoff score of 21 [20-24], at least 214 participants were needed for logistic regression analysis including 15 predictor variables. Anticipating a 10\% exclusion rate, the sample size was further increased to 236 participants. 
Table 1 Characteristics of 218 family caregiver and patient dyads

\begin{tabular}{|c|c|c|}
\hline Variable & Description & \\
\hline \multicolumn{3}{|l|}{ Family caregivers } \\
\hline Age $(n=215)$ & Median (IQR) & $35(29-44)$ \\
\hline \multicolumn{3}{|l|}{$\operatorname{Sex}(n=218)$} \\
\hline Female & $n(\%)$ & $127(58.3)$ \\
\hline Male & $n(\%)$ & $91(41.7)$ \\
\hline \multicolumn{3}{|l|}{ Marital status $(n=217)$} \\
\hline Married & $n(\%)$ & $149(68.7)$ \\
\hline Single & $n(\%)$ & $53(24.4)$ \\
\hline Divorced & $n(\%)$ & $11(5.1)$ \\
\hline Widow & $n(\%)$ & $4(1.8)$ \\
\hline \multicolumn{3}{|l|}{ Education $(n=218)$} \\
\hline University & $n(\%)$ & $91(41.7)$ \\
\hline High school & $n(\%)$ & $66(30.3)$ \\
\hline Less than high school & $n(\%)$ & $41(18.8)$ \\
\hline Illiterate & $n(\%)$ & $20(9.2)$ \\
\hline \multicolumn{3}{|l|}{ Employment $(n=218)$} \\
\hline Full time & $n(\%)$ & $61(28)$ \\
\hline Part time & $n(\%)$ & $28(12.8)$ \\
\hline Stopped for caregiving & $n(\%)$ & $31(14.2)$ \\
\hline None & $n(\%)$ & $98(45)$ \\
\hline \multicolumn{3}{|l|}{ Relation to the patient $(n=218)$} \\
\hline Daughter & $n(\%)$ & $60(27.5)$ \\
\hline Son & $n(\%)$ & $53(24.3)$ \\
\hline Sister & $n(\%)$ & $29(13.3)$ \\
\hline Husband & $n(\%)$ & $22(10.1)$ \\
\hline Wife & $n(\%)$ & $14(6.4)$ \\
\hline Brother & $n(\%)$ & $12(5.5)$ \\
\hline Other & $n(\%)$ & $28(12.8)$ \\
\hline \multicolumn{3}{|l|}{ Comorbidities $(n=204)$} \\
\hline Back pain & $n(\%)$ & $27(13.2)$ \\
\hline Hypertension & $n(\%)$ & $20(9.8)$ \\
\hline Diabetes mellitus & $n(\%)$ & $10(4.9)$ \\
\hline Other & $n(\%)$ & $21(10.3)$ \\
\hline Living with the patient $(n=218)$ & $n(\%)$ & $153(70.2)$ \\
\hline Number of other caregivers $(n=209)$ & Median (IQR) & $2(1-3)$ \\
\hline \multicolumn{3}{|l|}{ Patient characteristics } \\
\hline Age $(n=217)$ & Median (IQR) & $55(46-63)$ \\
\hline \multicolumn{3}{|l|}{$\operatorname{Sex}(n=218)$} \\
\hline Female & $n(\%)$ & $164(75.2)$ \\
\hline Male & $n(\%)$ & $54(24.8)$ \\
\hline \multicolumn{3}{|l|}{ 1ry cancer $(n=214)$} \\
\hline Breast & $n(\%)$ & $77(36)$ \\
\hline Colorectal & $n(\%)$ & $31(14.5)$ \\
\hline Lung & $n(\%)$ & $28(13.1)$ \\
\hline Pancreas & $n(\%)$ & $17(7.9)$ \\
\hline Hematological & $n(\%)$ & $12(5.6)$ \\
\hline Sarcoma & $n(\%)$ & $10(4.7)$ \\
\hline Other & $n(\%)$ & $39(18.2)$ \\
\hline Distant metastases $(n=197)$ & $n(\%)$ & $168(85.3)$ \\
\hline
\end{tabular}

Table 1 (continued)

\begin{tabular}{lll}
\hline Variable & Description & \\
\hline Aware of cancer diagnosis $(n=218)$ & $n(\%)$ & $186(85.3)$ \\
Expecting cure for his/her cancer $(n=185)$ & $n(\%)$ & $140(75.7)$ \\
Treatment plan $(n=214)$ & & \\
$\quad$ Best supportive care & $n(\%)$ & $49(22.9)$ \\
Palliative anti-cancer treatment & $n(\%)$ & $165(77.1)$ \\
\hline
\end{tabular}

\section{Statistical methods}

Categorical data were described as numbers and percentages while continuous as means and standard deviations. Independent sample $\mathrm{t}$-test was used to determine the significance of difference in continuous variables between two groups and one way ANOVA for more than two groups. Pearson's correlation coefficient was used to study the significance of correlation between two continuous variables.

Statistical analysis was done using MedCalc ${ }^{\circledR}$ Statistical Software version 20 (MedCalc Software Ltd., Ostend, Belgium; https://www.medcalc.org; 2021).

\section{Results}

From 244 participating FCs, 218 (89.3\%) were included in the analysis, $23(9.4 \%)$ were excluded and $3(1.2 \%)$ withdrew from the study. The causes of exclusion were missing patient's data (11), repeated patient (5), >6 missing ZBI items (2), no incurable cancer (2), no confirmed cancer diagnosis (1), < 18 years of age (1) and being a friend (1). 165 (75.7\%) FCs were recruited from Egypt and 53 (24.3\%) from Saudi Arabia. 166 (54.2\%) FCs were interviewed in the outpatient setting and $98(45.8 \%)$ in the inpatient.

The characteristics of included FCs, patients and cancer are illustrated in Table 1. As perceived by FCs, the majority of patients were aware of the diagnosis of cancer but not its prognosis. The majority of diagnosis-aware patients expected cure for their disease.

The details of assistance with ADLs provided by FCs and the level of assistance are shown in Table 2. The majority $(194 / 218,89 \%)$ of FCs assisted with at least one of the screened ADLs and three-quarters of them provided level 3 assistance with basic ADLs.

The majority $(209 / 218,96 \%)$ of participating FCs answered all items of the ZBI-22. The mean (SD) ZBI-22 score was 23.4 (9.3) and the median (IQR) was 23 (1631 ). Using the ZBI-22 cutoff score of 21, 128/218 (58.7\%) FCs had significant $C B$ (total score $\geq 21$ ). The details of the response of FCs to the 22 items of the ZBI-22 are shown in Table 3.

The level of assistance with basic ADLs, best supportive care treatment plan and higher ECOG score were 
Table 2 Family caregivers' assistance with basic activities of daily living and its level

\begin{tabular}{|c|c|}
\hline & $n(\%)$ \\
\hline \multicolumn{2}{|l|}{ Assistance with early-loss ADL } \\
\hline Dressing $(n=217)$ & $146(67.3)$ \\
\hline Combing hair $(n=217)$ & $102(47)$ \\
\hline Brushing of teeth $(n=213)$ & $68(31.9)$ \\
\hline Any early loss ADL $(n=218)$ & $153(70.2)$ \\
\hline \multicolumn{2}{|l|}{ Assistance with middle-loss ADL } \\
\hline Toilet use $(n=217)$ & $149(68.7)$ \\
\hline Cleansing $(n=215)$ & $84(39.1)$ \\
\hline Moving between locations ( $n=216$ ) & $175(81)$ \\
\hline Transfer to/from chair $(n=216)$ & $155(71.8)$ \\
\hline Bathing $(n=216)$ & $122(56.5)$ \\
\hline Any middle loss ADL $(n=218)$ & $190(87.2)$ \\
\hline \multicolumn{2}{|l|}{ Assistance with late-loss ADL } \\
\hline Bed mobility $(n=216)$ & $149(69)$ \\
\hline Eating $(n=216)$ & $136(63)$ \\
\hline Any late loss ADL $(n=217)$ & $167(77)$ \\
\hline \multicolumn{2}{|l|}{ Level of assistance provided by family caregiver with basic ADLs ( $n=218$ ) } \\
\hline Level 1 (no assistance / assistance with early-loss ADL) & $26(11.9)$ \\
\hline Level 2 (assistance with middle-loss ADL \pm assistance with early-loss ADL) & $25(11.5)$ \\
\hline Level 3 (assistance with late loss ADL \pm assistance with early / middle-loss ADL) & $167(76.6)$ \\
\hline
\end{tabular}

significantly associated with $\mathrm{CB}$ in univariate analysis (Table 4). Logistic regression analysis showed that only level 3 assistance with basic ADLs independently associated with $\mathrm{CB}$.

The ZBI-22 total score according to the level of assistance with ADLs provided by FCs is shown in Fig. 1. The mean ZBI-22 score for level 1 and level 2 was below the cutoff point of significant $\mathrm{CB}$ (mean $[\mathrm{SD}]=15.5$ [8.7] and 19.9 [9.3], respectively), while it was above the cutoff point for level 3 assistance (mean $[S D]=25.2$ [8.6]).

\section{Discussion}

This study, conducted in two Eastern Mediterranean countries, showed that a substantial proportion of FCs of incurable cancer patients experience significant CB. Among the studied variables, the only one that predicted CB was FCs' assistance with late-loss basic ADLs.

The high prevalence of $\mathrm{CB}$ among FCs of incurable cancer in this study is not surprising and agrees with the findings of other studies conducted in different settings from around the world. The prevalence of $\mathrm{CB}$ among FCs of cancer patients in general using the ZBI-22 cutoff point of 21 ranged widely from 37 to $82 \%$ in other studies $[9,20-25]$. The $59 \%$ prevalence of CB found in this study falls in the middle of this range. These studies included FCs of cancer patients at different stages and some focused on a certain type of cancer.
The mean ZBI-22 score in this study was 23, which is largely similar to that reported in other studies that included FCs of advanced cancer patients. In a study from the United Kingdom that included 105 informal caregivers of advanced cancer patients, the mean ZBI22 score was 23 [26]. Similarly, the mean ZBI-22 score was 23 in a study from a palliative care unit in Malaysia that included 249 informal caregivers of patients with life-limiting illnesses of whom $74 \%$ had malignancy [27]. In a Thai study, the mean ZBI-22 score of 19 among 150 informal caregivers of elderly advanced cancer patients [25]. These findings suggest that there are common factors contributing to $\mathrm{CB}$ among FCs of patients with advanced cancer in different cultures and socioeconomic statuses.

Previous studies identified factors that may determine the presence and severity of CB; such as the absence of a helper, longer stay in the hospital, marital status, education of caregivers, type of treatment facility and the time elapsed since cancer diagnosis [9-11]. In the current study, the only variable that associated independently with significant $\mathrm{CB}$ was the assistance with late-loss ADLs. Although assistance with ADLs is perceived as a contributor to $\mathrm{CB}$, the evidence that support this perception is not consistent. Goldstein et al. included in their study caregivers of patients with terminal cancer and found no significant association between the number of ADLs the caregivers assist with and higher CB [28]. 
Table 3 Response of family caregivers to the ZBI-22 items

\begin{tabular}{|c|c|c|c|c|c|c|c|}
\hline Item & $n$. & Response $n$. (\%) & & & & & Mean (SD) \\
\hline & & $\begin{array}{l}0 \\
\text { (never) }\end{array}$ & $\begin{array}{l}1 \\
\text { (rarely) }\end{array}$ & $\begin{array}{l}2 \\
\text { (sometimes) }\end{array}$ & $\begin{array}{l}3 \\
\text { (quite frequently) }\end{array}$ & $\begin{array}{l}4 \\
\text { (nearly always) }\end{array}$ & \\
\hline $\begin{array}{l}\text { 1. Do you feel that your relative asks for more } \\
\text { help than he/she needs? }\end{array}$ & 218 & $133(61)$ & $22(10.1)$ & $35(16.1)$ & $24(11)$ & $4(1.8)$ & $0.83(1.2)$ \\
\hline $\begin{array}{l}\text { 2. Do you feel that because of the time you } \\
\text { spend with your relative that you don't have } \\
\text { enough time for yourself? }\end{array}$ & 218 & $117(53.7)$ & $26(11.9)$ & $49(22.5)$ & $23(10.6)$ & $3(1.4)$ & $0.94(1.2)$ \\
\hline $\begin{array}{l}\text { 3. Do you feel stressed between caring for your } \\
\text { relative and trying to meet other responsibilities } \\
\text { for your family or work? }\end{array}$ & 217 & 86 (39.6) & $23(10.6)$ & $59(27.2)$ & 41 (18.9) & $8(3.7)$ & $1.36(1.3)$ \\
\hline $\begin{array}{l}\text { 4. Do you feel embarrassed over your relative's } \\
\text { behaviour? }\end{array}$ & 218 & $184(84.4)$ & $15(6.9)$ & $15(6.9)$ & $3(1.4)$ & $1(0.5)$ & $0.27(0.7)$ \\
\hline $\begin{array}{l}5 . \text { Do you feel angry when you are around your } \\
\text { relative? }\end{array}$ & 217 & $194(89.4)$ & $14(6.5)$ & $8(3.7)$ & $1(0.5)$ & 0 & $0.15(0.5)$ \\
\hline $\begin{array}{l}\text { 6. Do you feel that your relative currently affects } \\
\text { your relationship with other family members or } \\
\text { friends in a negative way? }\end{array}$ & 217 & $162(74.7)$ & $19(8.8)$ & $30(13.8)$ & $6(2.8)$ & 0 & $0.45(0.8)$ \\
\hline $\begin{array}{l}\text { 7. Are you afraid what the future holds for your } \\
\text { relative? }\end{array}$ & 216 & $35(16.2)$ & $7(3.2)$ & $46(21.3)$ & $101(46.8)$ & $27(12.5)$ & $2.36(1.2)$ \\
\hline $\begin{array}{l}\text { 8. Do you feel your relative is dependent upon } \\
\text { you? }\end{array}$ & 217 & $15(6.9)$ & $16(7.4)$ & $46(21.2)$ & $94(43.3)$ & $46(21.2)$ & $2.65(1.1)$ \\
\hline $\begin{array}{l}\text { 9. Do you feel strained when you are around } \\
\text { your relative? }\end{array}$ & 217 & $156(71.9)$ & $21(9.7)$ & $31(14.3)$ & $7(3.2)$ & $2(0.9)$ & $0.52(0.9)$ \\
\hline $\begin{array}{l}\text { 10. Do you feel your health has suffered } \\
\text { because of your involvement with your relative? }\end{array}$ & 217 & $150(69.1)$ & $26(12)$ & $29(13.4)$ & $12(5.5)$ & 0 & $0.55(0.9)$ \\
\hline $\begin{array}{l}\text { 11. Do you feel that you don't have as much } \\
\text { privacy as you would like, because of your relative? }\end{array}$ & 217 & $151(69.6)$ & $29(13.4)$ & $25(11.5)$ & $11(5.1)$ & $1(0.5)$ & $0.54(0.9)$ \\
\hline $\begin{array}{l}\text { 12. Do you feel that your social life has suffered } \\
\text { because you are caring for your relative? }\end{array}$ & 217 & $132(60.8)$ & $23(10.6)$ & $47(21.7)$ & $13(6)$ & $2(0.9)$ & $0.76(1.1)$ \\
\hline $\begin{array}{l}\text { 13. Do you feel uncomfortable about having } \\
\text { friends over, because of your relative? }\end{array}$ & 216 & $167(77.3)$ & $21(9.7)$ & $18(8.3)$ & $9(4.2)$ & $1(0.5)$ & $0.41(0.9)$ \\
\hline $\begin{array}{l}\text { 14. Do you feel that your relative seems to } \\
\text { expect you to take care of him/her, as if you were } \\
\text { the only one he/she could depend on }\end{array}$ & 215 & $37(17.2)$ & $12(5.6)$ & $42(19.5)$ & 89 (41.4) & $35(16.3)$ & $2.34(1.3)$ \\
\hline $\begin{array}{l}\text { 15. Do you feel that you don't have enough } \\
\text { money to care for your relative, in addition to the } \\
\text { rest of your expenses? }\end{array}$ & 218 & 43 (19.7) & $15(6.9)$ & $59(27.1)$ & $81(37.2)$ & $20(9.2)$ & $2.1(1.3)$ \\
\hline $\begin{array}{l}\text { 16. Do you feel that you will be unable to take } \\
\text { care of your relative much longer? }\end{array}$ & 217 & $163(75.1)$ & $26(12)$ & $25(11.5)$ & $3(1.4)$ & 0 & $0.39(0.7)$ \\
\hline $\begin{array}{l}\text { 17. Do you feel you have lost control of your life } \\
\text { since your relative's illness? }\end{array}$ & 217 & $124(57.1)$ & $26(12)$ & $46(21.2)$ & $19(8.8)$ & $2(0.9)$ & $0.84(1.1)$ \\
\hline $\begin{array}{l}\text { 18. Do you wish you could just leave the care of } \\
\text { your relative to someone else? }\end{array}$ & 218 & $184(84.4)$ & $18(8.3)$ & $13(6)$ & $3(1.4)$ & 0 & $0.24(0.6)$ \\
\hline $\begin{array}{l}\text { 19. Do you feel uncertain about what to do } \\
\text { about your relative? }\end{array}$ & 216 & 115 (53.2) & $19(8.8)$ & $61(28.2)$ & $20(9.3)$ & $1(0.5)$ & $0.95(1.1)$ \\
\hline $\begin{array}{l}20 \text {. Do you feel you should be doing more for } \\
\text { your relative? }\end{array}$ & 218 & $51(23.4)$ & $19(8.7)$ & 63 (28.9) & 74 (33.9) & $11(5)$ & 1.89 (1.3) \\
\hline \multirow{2}{*}{$\begin{array}{l}21 \text {. Do you feel you could do a better job in } \\
\text { caring for your relative? }\end{array}$} & 218 & $35(16.1)$ & $13(6)$ & $83(38.1)$ & 77 (35.3) & $10(4.6)$ & $2.1(1.1)$ \\
\hline & & $\begin{array}{l}0 \\
\text { (not at all) }\end{array}$ & $\begin{array}{l}1 \\
\text { (a little) }\end{array}$ & $\begin{array}{l}2 \\
\text { (moderately) }\end{array}$ & $\begin{array}{l}3 \\
\text { (quite a bit) }\end{array}$ & $\begin{array}{l}4 \\
\text { (extremely) }\end{array}$ & \\
\hline $\begin{array}{l}\text { 22. Overall, how burdened do you feel in caring } \\
\text { for your relative? }\end{array}$ & 218 & $120(55)$ & $37(17)$ & $37(17)$ & $22(10.1)$ & $2(0.9)$ & $0.85(1.1)$ \\
\hline
\end{tabular}

Another Thai study found no independent association between assistance with ADLs and higher CB [25]. In our study, we examined the association between the level of assistance with basic ADLs, rather than the number of ADLs or assistance in general. We found that it is the assistance with late-loss ADLs is the one that contribute 
Table 4 The relationship between caregiver burden and the studied variables

\begin{tabular}{|c|c|c|c|c|c|c|}
\hline & & \multirow{2}{*}{\multicolumn{2}{|c|}{$\begin{array}{l}\text { Univariate analysis } \\
\text { Caregiver burden }\end{array}$}} & \multirow[b]{4}{*}{$P$ value } & \multicolumn{2}{|c|}{ Regression analysis } \\
\hline & & & & & \multirow[t]{3}{*}{ OR $(95 \% \mathrm{Cl})$} & \multirow[t]{3}{*}{$P$ value } \\
\hline & & $\begin{array}{l}\text { No } \\
\text { (ZBI-22 score }<21)\end{array}$ & $\begin{array}{l}\text { Yes } \\
\text { (ZBI-22 score } \geq 21 \text { ) }\end{array}$ & & & \\
\hline & & $n(\%)$ & & & & \\
\hline \multirow[t]{3}{*}{$\begin{array}{l}\text { Level of assistance with basic } \\
\text { ADLs provided by caregivers }\end{array}$} & $\begin{array}{l}\text { Level } 1 \text { (no assistance / } \\
\text { assistance with early-loss ADLs) }\end{array}$ & $20(76.9)$ & $6(23.1)$ & $<0.0001$ & Ref. & \\
\hline & $\begin{array}{l}\text { Level } 2 \text { (assistance with middle- } \\
\text { loss ADL } \pm \text { assistance with } \\
\text { early-loss ADL) }\end{array}$ & $14(56)$ & $11(44)$ & & $\begin{array}{l}1.79 \\
(0.51-6.3)\end{array}$ & 0.367 \\
\hline & $\begin{array}{l}\text { Level } 3 \text { (assistance with late-loss } \\
\text { ADL } \pm \text { assistance with early / } \\
\text { middle-loss ADL) }\end{array}$ & $56(33.5)$ & $111(66.5)$ & & $\begin{array}{l}3.38 \\
(1.18-9.72)\end{array}$ & 0.024 \\
\hline \multirow[t]{2}{*}{ Sex of caregiver } & Female & $54(42.5)$ & $73(57.5)$ & 0.662 & - & - \\
\hline & Male & $36(39.6)$ & $55(60.4)$ & & - & \\
\hline \multirow[t]{2}{*}{ Sex of patient } & Female & $71(43.3)$ & $93(56.7)$ & 0.295 & - & - \\
\hline & Male & $19(35.2)$ & $35(64.8)$ & & - & \\
\hline \multirow[t]{2}{*}{ Marital status of caregiver } & Married & $65(43.6)$ & $84(56.4)$ & 0.248 & - & - \\
\hline & Other & $24(35.3)$ & $44(64.7)$ & & - & \\
\hline \multirow[t]{3}{*}{ Education level of caregiver } & High school / University & $63(40.1)$ & $94(59.9)$ & 0.506 & - & - \\
\hline & Less than high school & $20(48.8)$ & $21(51.2)$ & & - & \\
\hline & Illiterate & $7(35)$ & $13(65)$ & & - & \\
\hline \multirow[t]{2}{*}{ Employment of caregiver } & No & $54(41.9)$ & $75(58.1)$ & 0.836 & - & - \\
\hline & Yes & $36(40.4)$ & $53(59.6)$ & & - & \\
\hline \multirow[t]{4}{*}{ Relation to the patient } & Daughter / son & $45(39.8)$ & $68(60.2)$ & 0.263 & - & - \\
\hline & Sister / brother & $19(46.3)$ & $22(53.7)$ & & - & \\
\hline & Wife / Husband & $11(30.6)$ & $25(69.4)$ & & - & \\
\hline & Other & $15(53.6)$ & $13(46.4)$ & & - & \\
\hline \multirow[t]{2}{*}{ Caregiver living with the patient } & No & $31(47.7)$ & $34(52.3)$ & 0.211 & - & - \\
\hline & Yes & $59(38.6)$ & $94(61.4)$ & & - & \\
\hline \multirow[t]{2}{*}{ Caregiver has comorbidity } & No & $61(42.7)$ & $82(57.3)$ & 0.661 & - & - \\
\hline & Yes & $24(39.3)$ & $37(60.7)$ & & - & \\
\hline \multirow[t]{2}{*}{ Primary cancer } & Breast & $37(48.1)$ & $40(51.9)$ & 0.099 & - & - \\
\hline & Other & $50(36.5)$ & $87(63.5)$ & & - & \\
\hline \multirow[t]{3}{*}{ Anti-cancer treatment plan } & Best supportive care & $13(26.5)$ & $36(73.5)$ & 0.018 & Ref. & \\
\hline & Palliative anti-cancer & $75(45.5)$ & $90(54.5)$ & & $\begin{array}{l}0.75 \\
(0.34-1.67)\end{array}$ & 0.482 \\
\hline & & Mean (SD) & & $P$ value & & \\
\hline Age of caregiver & & $35.8(10.7)$ & $37(11)$ & 0.399 & - & - \\
\hline \multirow[t]{2}{*}{ Age of patient } & & $55.2(13.6)$ & $53.8(13.5)$ & 0.446 & - & - \\
\hline & & Median (IQR) & & $P$ value & & \\
\hline Number of other carers & & $2(1-3)$ & $2(1-3)$ & 0.407 & - & - \\
\hline ECOG performance scale & & $2(2-3)$ & $3(2-3)$ & 0.005 & $\begin{array}{l}1.34 \\
(0.88-2.04)\end{array}$ & 0.177 \\
\hline
\end{tabular}

ECOG Eastern Cooperative Oncology Group, IQR Inter-quartile range, OR Odds ratio, SD Standard deviation

to $\mathrm{CB}$. This is supported by the results of the recent study conducted by Schwartz et al. [5]. They found that only the assistance with feeding and toileting are independently associated with higher $\mathrm{CB}$ among caregivers of patients with cancer of different stages.
Although it may be seen by some as unnecessary, we detailed in the results section the response of FCs to the 22 items of the ZBI-22. This may serve as a guide for future research/interventions to minimize the $\mathrm{CB}$ of FCs in our region. Only 5 items out of the 22 scored 


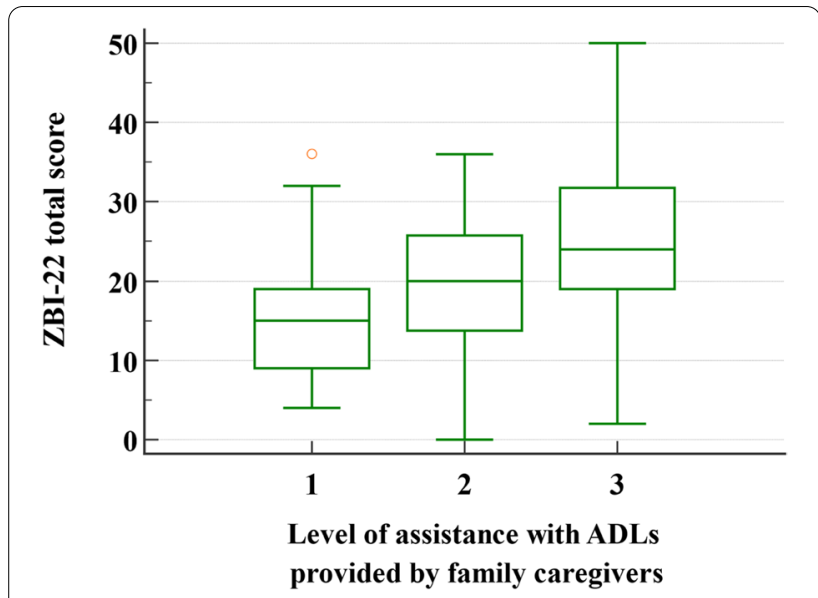

Fig. 1 ZBI-22 score according to the level of assistance with basic ADLs provided by family caregivers

in average $>2$ on the $0-4$ scale. One of these 5 items is the financial concerns. In a study from another country in the EMRO region (Iran), no enough income for living expenses was significantly associated with CB [14]. This may be a target for interventions dealing with $\mathrm{CB}$. Another example is the fear of FCs of what the future holds for their related patient, which scored in average 2.4 on the $0-4$ scale. Meeting the information needs of FCs and supporting them psychosocially may ameliorate their fears and consequently the burden they suffer.

A limitation of the study is that we did not study all factors that had been found to contribute to $\mathrm{CB}$ in other studies like the social network index of caregivers and their activity restriction [28]. Another limitation is the purposive-convenience sampling method used.

In conclusion, FCs of patients with incurable cancer experience significant $\mathrm{CB}$ in our region. Routine screening for $\mathrm{CB}$ is warranted among FCs of incurable cancer patients who assist their related patients with the basic ADLs, especially the late-loss ones. There is a need for further research to explore the needs of FCs of incurable cancer patients in the EMRO region and how to address these needs.

\section{Abbreviations}

ADLs: Activities of daily living; CB: Caregiver burden; ECOG: Eastern Cooperative Oncology Group; FCs: Family caregivers; IQR: Inter-quartile range; OR: Odds ratio; SD: Standard deviation; ZBI-22: The 22-item Zarit Burden Interview.

\section{Acknowledgements}

Not applicable.

\section{Authors' contributions}

SAA: Conception and design of the work, analysis and interpretation of data, drafting the work, approval of submitted version and accountability for all aspects of the work. RN: Acquisition of data, revision of the work, approval of submitted version and accountability for all aspects of the work. AH: Design of the work, acquisition of data, revision of the work, approval of submitted version and accountability for all aspects of the work. RF: Acquisition of data, revision of the work, approval of submitted version and accountability for all aspects of the work. AA: Acquisition of data, revision of the work, approval of submitted version and accountability for all aspects of the work. $\mathrm{MOH}$ : Acquisition of data, revision of the work, approval of submitted version and accountability for all aspects of the work. MA: Design of the work, revision of the work, approval of submitted version and accountability for all aspects of the work. SAla: Design of the work, revision of the work, approval of submitted version and accountability for all aspects of the work. SAlg: Design of the work, revision of the work, approval of submitted version and accountability for all aspects of the work. AE: Design of the work, revision of the work, approval of submitted version and accountability for all aspects of the work.

Funding

Not applicable.

Availability of data and materials

The datasets used and/or analysed during the current study are available from the corresponding author on reasonable request.

\section{Declarations}

\section{Ethics approval and consent to participate}

The study was approved by the King Saud Medical City Institutional Review Board (Approval \# H1RI-16-Apr19-01). Further approval was obtained from the Scientific Committee of Kasr Al-Ainy Center of Clinical Oncology and Nuclear Medicine, Kasr Al-Ainy School of Medicine, Cairo University. All participants signed an informed written consent before participation.

\section{Consent for publication}

Not applicable.

\section{Competing interests}

The authors declare that they have no competing interests.

\section{Author details}

${ }^{1}$ Palliative Care Unit, Hemato-Oncology Department, King Saud Medical City, Riyadh, Saudi Arabia. ${ }^{2}$ Palliative Medicine Unit, Kasr Al-Ainy Center of Clinical Oncology and Nuclear Medicine, Kasr Al-Ainy School of Medicine, Cairo University, Cairo, Egypt. ${ }^{3}$ Oncology Department, Kasr Al-Ainy Center of Clinical Oncology and Nuclear Medicine, Kasr Al-Ainy School of Medicine, Cairo University, Cairo, Egypt. ${ }^{4}$ The Royal Wolverhampton NHS Trust, New Cross Hospital, Wolverhampton, UK. ${ }^{5}$ Oncology Unit, Hemato-Oncology Department, King Saud Medical City, Riyadh, Saudi Arabia. ${ }^{6}$ Medical Oncology Department, South Egypt Cancer Institute, Assiut University, Assiut, Egypt.

Received: 24 July 2021 Accepted: 28 September 2021

Published online: 18 October 2021

\section{References}

1. International Agency for Research on Cancer. Population fact sheets: WHO East Mediterranean (EMRO); 2020 (https://gco.iarc.fr/today/data/ factsheets/populations/993-who-east-mediterranean-emro-fact-sheets. pdf, accessed: 18 June 2021).

2. World Health Organization. National Cancer Control Programmes: policies and managerial guidelines. 2nd ed. Geneva: World Health Organization; 2002.

3. Glajchen $M$. The emerging role and needs of family caregivers in cancer care. J Support Oncol. 2004;2(2):145-55.

4. Adashek JJ, Subbiah IM. Caring for the caregiver: a systematic review characterising the experience of caregivers of older adults with advanced cancers. ESMO Open. 2020;5(5):e000862. https://doi.org/10.1136/esmoo pen-2020-000862.

5. Schwartz K, Beebe-Dimmer J, Hastert TA, Ruterbusch JJ, Mantey J, Harper $F$, et al. Caregiving burden among informal caregivers of African American cancer survivors. J Cancer Surviv. 2020. https://doi.org/10.1007/s11764020-00956-x, https://doi.org/10.1007/s11764-020-00956-x. 
6. Lambert SD, Harrison JD, Smith E, Bonevski B, Carey M, Lawsin C, et al. The unmet needs of partners and caregivers of adults diagnosed with cancer: a systematic review. BMJ Support Palliat Care. 2012;2(3):224-30. https:// doi.org/10.1136/bmjspcare-2012-000226.

7. Sklenarova H, Krümpelmann A, Haun MW, Friederich HC, Huber J, Thomas $M$, et al. When do we need to care about the caregiver? Supportive care needs, anxiety, and depression among informal caregivers of patients with cancer and cancer survivors. Cancer. 2015;121(9):1513-9. https://doi. org/10.1002/cncr.29223.

8. Wang T, Molassiotis A, Chung BPM, Tan JY. Unmet care needs of advanced cancer patients and their informal caregivers: a systematic review. BMC Palliat Care. 2018;17(1):96. https://doi.org/10.1186/s12904-018-0346-9.

9. Lukhmana S, Bhasin SK, Chhabra P, Bhatia MS. Family caregivers' burden: a hospital based study in 2010 among cancer patients from Delhi. Indian J Cancer. 2015;52(1):146-51. https://doi.org/10.4103/0019-509X.175584.

10. Mirsoleymani SR, Rohani C, Matbouei M, Nasiri M, Vasli P. Predictors of caregiver burden in Iranian family caregivers of cancer patients. J Educ Health Promot. 2017;6:91. https://doi.org/10.4103/jehp.jehp_137_16.

11. Seo YJ, Park H. Factors influencing caregiver burden in families of hospitalized patients with lung Cancer. J Clin Nurs. 2019;28(9-10):1979-89. https://doi.org/10.1111/jocn.14812.

12. Tang Y. Caregiver burden and bereavement among family caregivers who lost terminally ill cancer patients. Palliat Support Care. 2019;17(5):515-22. https://doi.org/10.1017/S1478951518001025.

13. Abbasi A, Mirhosseini S, Basirinezhad MH, Ebrahimi H. Relationship between caring burden and quality of life in caregivers of cancer patients in Iran. Support Care Cancer. 2020;28(9):4123-9. https://doi.org/10.1007/ s00520-019-05240-y.

14. Vahidi M, Mahdavi N, Asghari E, Ebrahimi H, Eivazi Ziaei J, Hosseinzadeh $M$, et al. Other side of breast Cancer: factors associated with caregiver burden. Asian Nurs Res (Korean Soc Nurs Sci). 2016;10(3):201-6. https:// doi.org/10.1016/j.anr.2016.06.002.

15. Ghazwani EY, Al-Shehri AA, Alghamdi FA. Assessment of burden and stress among caregivers of terminally ill patients in a Saudi University hospital: a cross-sectional study. Cureus. 2021;13(3):e14215. https://doi. org/10.7759/cureus.14215.

16. Al Wakeel JS, Bayoumi MM. Caregiver burden among peritoneal dialysis and hemodialysis family in Saudi Arabia. Kuwait Med J. 2016;48(3):197-201.

17. Zarit Burden Interview: Instructions for Administration, Scoring, and Interpretation. (https://mapi-trust.org/questionnaires/zbi/\#instructions, accessed 12 May 2021)

18. Zarit SH, Orr RD, Zarit JM. The hidden victims of Alzheimer's disease: families under stress. New York: New York University Press; 1985.
19. Morris JN, Fries BE, Morris SA. Scaling ADLs within the MDS. J Gerontol A Biol Sci Med Sci. 1999;54(11):M546-53. https://doi.org/10.1093/gerona/ 54.11.m546.

20. Bayen E, Laigle-Donadey F, Prouté M, Hoang-Xuan K, Joël ME, Delattre JY. The multidimensional burden of informal caregivers in primary malignant brain tumor. Support Care Cancer. 2017;25(1):245-53. https://doi.org/10. 1007/s00520-016-3397-6.

21. Germain V, Dabakuyo-Yonli TS, Marilier S, Putot A, Bengrine-Lefevre L, Arveux $\mathrm{P}$, et al. Management of elderly patients suffering from cancer: assessment of perceived burden and of quality of life of primary caregivers. J Geriatr Oncol. 2017;8(3):220-8. https://doi.org/10.1016/j.jgo.2016.12. 001.

22. Wood R, Taylor-Stokes G, Smith F, Chaib C. The humanistic burden of advanced non-small cell lung cancer (NSCLC) in Europe: a realworld survey linking patient clinical factors to patient and caregiver burden. Qual Life Res. 2019;28(7):1849-61. https://doi.org/10.1007/ s11136-019-02152-6.

23. Akpan-Idiok PA, Ehiemere IO, Asuquo EF, Chabo JAU, Osuchukwu EC. Assessment of burden and coping strategies among caregivers of cancer patients in sub-Saharan Africa. World J Clin Oncol. 2020;11(12):1045-63. https://doi.org/10.5306/wjco.v11.i12.1045.

24. Onyeneho CA, llesanmi RE. Burden of care and perceived psycho-social outcomes among family caregivers of patients living with Cancer. Asia Pac J Oncol Nurs. 2021;8(3):330-6. https://doi.org/10.4103/2347-5625. 308678.

25. Chindaprasirt J, Limpawattana P, Pakkaratho P, Wirasorn K, Sookprasert $A$, Kongbunkiat $K$, et al. Burdens among caregivers of older adults with advanced cancer and risk factors. Asian Pac J Cancer Prev. 2014;15(4):1643-8. https://doi.org/10.7314/apjcp.2014.15.4.1643.

26. Harding R, Gao W, Jackson D, Pearson C, Murray J, Higginson IJ. Comparative analysis of informal caregiver burden in advanced Cancer, dementia, and acquired brain injury. J Pain Symptom Manag. 2015;50(4):445-52. https://doi.org/10.1016/j.jpainsymman.2015.04.005.

27. Ahmad Zubaidi ZS, Ariffin F, Oun CTC, Katiman D. Caregiver burden among informal caregivers in the largest specialized palliative care unit in Malaysia: a cross sectional study. BMC Palliat Care. 2020;19(1):186. https:// doi.org/10.1186/s12904-020-00691-1.

28. Goldstein NE, Concato J, Fried TR, KasI SV, Johnson-Hurzeler R, Bradley EH. Factors associated with caregiver burden among caregivers of terminally ill patients with cancer. J Palliat Care. 2004;20(1):38-43.

\section{Publisher's Note}

Springer Nature remains neutral with regard to jurisdictional claims in published maps and institutional affiliations.
Ready to submit your research? Choose BMC and benefit from:

- fast, convenient online submission

- thorough peer review by experienced researchers in your field

- rapid publication on acceptance

- support for research data, including large and complex data types

- gold Open Access which fosters wider collaboration and increased citations

- maximum visibility for your research: over $100 \mathrm{M}$ website views per year

At BMC, research is always in progress.

Learn more biomedcentral.com/submissions 